\title{
Editorial
}

\section{Wine and health}

In 1970 , the seven countries study ${ }^{1}$ showed there was a relatively lower rate of coronary heart disease in Mediterranean countries and that this difference was attributed to diet. In 1980-95 many studies demonstrated a favourable effect of moderate alcohol consumption on the incidence and secondary prevention of coronary heart disease. If one considers that wine consumption may have some protective effects against coronary heart disease, a number of questions arise:

- is there any specific property of wine compared with other alcoholic beverages?

- does wine have an advantage over fruit and vegetables that are also rich in flavonoids?

- if so, should we recommend red or white wine or, perhaps a wine from a precise appellation, and what might be the daily "dose"?

To answer the first question, only transverse or retrospective studies are possible; a prospective study seems impractical-imagine a cohort of many thousands randomised for many years to water or to a daily amount of some alcoholic beverage without any flavour, or to the "wrong" wine associated with the same food in all groups! What about dropout, cost of drinking, addictions, overdose, cross over, and side effects? Furthermore, it would be difficult to select wine drinkers and abstainers on a random basis - for example, in the case of our hospital, volunteer wine drinkers might belong to the red wine group because the hospital is located along the vineyards of chateau Haut Brion and many of the (voluntary) abstainers might be slim vegetarians or addicted to rigorous physical training and by no means representative of a control group.

\section{Alcohol, wine or grape juice?}

In the population of Boston the relative risk of myocardial infarction among moderate drinkers compared with abstainers was 0.45 , and Gaziano et al concluded that " . . .the strength and consistency of the observational and experimental evidence strongly suggests a causal link between light to moderate alcoholic beverage consumption and reduced risks of CHD" ${ }^{2}$; however they, similar to Rimm et $a l,{ }^{3}$ Friedman et $a l,{ }^{4}$ did not make any distinction between wine and beer or spirits. Klatsky et al found a protective effect from any alcoholic beverage and granted a minor additional benefit for beer in men and red wine in women. ${ }^{5}$

As early as 1979, St Léger et al showed an inverse relation between the rate of cardiovascular mortality and wine consumption, and a direct relation with the consumption of dairy fat in European countries. ${ }^{6}$ In 1987, Richard ${ }^{7}$ used the term "French paradox" to underline the contrast between a food rich in saturated fatty acids and a moderate coronary death rate similar to that in Mediterranean countries where dietary fat intake is much less than in France.

Renaud and de Lorgeril $^{8}$ popularised the French paradox when the MONICA study (monitoring of trends and determinants in cardiovascular disease) showed a very low mortality rate from ischaemic heart disease in France despite intakes of saturated fats and concentrations of blood cholesterol similar to people in the USA and UK. The annual coronary death rate for 100000 men aged 35 to 64 years was 78 in Toulouse, 348 in Belfast, and 380 in Glasgow. Moreover, a difference of cardiovascular mortality rate between Lille, Strasbourg, and Toulouse was in favour of the last where the consumption of fresh fruit, fresh vegetable, and wine was more important than in Strasbourg or Lille. Toulouse residents have a daily consumption of $380 \mathrm{ml}$ of wine (mostly red) and $40 \mathrm{ml}$ of beer, while people in Lille consume $267 \mathrm{ml}$ of wine and $237 \mathrm{ml}$ of beer each day. The resulting amount of alcohol is 33 and $36 \mathrm{~g} /$ day, respectively.

The Mediterranean diet is effective in secondary prevention of ischaemic heart disease. In a controlled study, after a mean follow up of 27 months, recurrent myocardial infarction, all cardiovascular events, and cardiac and total death were significantly decreased by $70 \%$ in the group consuming the Mediterranean diet. ${ }^{9}$ But wine is only one of many components, others - such as garlic, fresh fruits and vegetables, and olive oil-have high concentrations of linolenic and oleic acids, and vitamins $\mathrm{E}$ and $\mathrm{C}$. Moreover, the diet in Toulouse is very different from the Mediterranean diet: coconut and colza oil, and duck, goose, and pig fat are used much more than olive oil, the use of which is restricted to the south east of France. Those who know the recipes for cassoulet or goose preserve can hardly consider these models of light and digestible cooking.

Apart from coronary heart disease, the PAQUID study showed that daily consumption of three to five glasses of wine seems to increase longevity. ${ }^{10}$ To investigate incidence of Alzheimer's disease, 2273 people older than 65 years living in retirement homes in Gironde and Dordogne departments were followed for three years: among those who consumed alcohol, 95\% regularly drank red wine. The relative risk of dementia was 0.21 and of Alzheimer's disease 0.25 among the 318 who drank three or four glasses of wine each day compared with a relative risk of 1 in the 971 total abstainers $(\mathrm{p}<0.03)$. Among the 922 who drank no more than one or two glasses each day the relative risk was significantly reduced only for Alzheimer's disease (0.55).

There is also good news for the specific effect of wine from the Copenhagen city heart study. ${ }^{11}$ After $10-12$ years' follow up, the risk of dying of 6051 men and 7234 women was 1 for those who never drank wine compared with 0.51 for those who drank three to five glasses a day. For spirits the relative risk of dying increased from 1 to 1.34 for those drinking three to five glasses a day. A study of ischaemic heart disease mortality in Sweden showed a significant difference in favour of regular wine drinkers, especially in women, but no difference for beer and spirit drinkers. ${ }^{12}$

Much more provocative is the contest between wine and $\operatorname{scotch}^{13}$ : a negative correlation between the prevalence of peripheral vascular disease and the consumption of alcoholic beverages was found in Scotland, but multivariate analysis and age adjustment showed that wine drinkers were protected compared to the beer and spirits consumers. This protective effect of wine was also maintained in smokers.

In a more prosaic aspect, the traditional belief that white wine has a protective effect against diarrhoea from crude oyster and shell fish consumption was reinforced by the 
demonstration that the antibacterial property of wine is superior to that of bismuth salicylate; however, tequila or pure alcoholic solution had a weak effect on colonies of salmonella, shigella, and Escherichia coli. ${ }^{14}$

The advice of Griffiths, with which we could hardly disagree, is "to consume one or two drinks a day, preferably with meals and perhaps red wine". ${ }^{15}$

\section{How does the wine work?}

The effects are threefold: antioxidant, vasodilating, and antithrombotic. Among the many phenolic compounds of wine, two deserve special mention: resveratrol and quercitin. The first is produced in autumn when grapes are attacked by Botrytis cinerea, the legendary agent of the "noble rod" of Sauternes. Except for Sauternes wine this mycelium is catastrophic for red wine: the higher the capacity of the grapes to produce resveratrol, the stronger is their resistance to Botrytis cinerea, and their aptitude to a delayed and prolonged maturation increases the concentration of tanins and glucosides. Resveratrol, a potent antioxidant produces an increase in high density lipoprotein (HDL) cholesterol by preventing low density lipoprotein (LDL) cholesterol oxidation. Frankel et al found that red wine diluted 1000-fold containing $10 \mu \mathrm{mol} / 1$ phenols inhibited LDL oxidation significantly more than did $\alpha$ tocopherol. ${ }^{16}$ The highest concentrations of resveratrol and other phenolic compounds are found in red wines, particularly in cabernet sauvignon grapes of Bordeaux, which face the moistness of the Gironde and the oceanic climate.

The vasodilator and antithrombotic effects of wine are related to quercitin and other potent nitric oxide donors, explaining their endothelium dependent vasodilator action. It is probable that the combination of tanins and alcohol enhances their antiaggregant and antioxidant effects as shown elegantly by Demrow et $a l,{ }^{17}$ using a dog model of mechanically stenosed coronary arteries and intimal damage. Periodic acute platelet mediated thrombus formation occurred, causing cyclic flow reductions (CFRs) in coronary blood flow. The CFRs were eliminated by the administration of $1.62(1.12) \mathrm{ml} / \mathrm{kg}$ red wine (Chateauneuf $\mathrm{du}$ pape 1990) given intravenously or $4.0 \mathrm{ml} / \mathrm{kg}$ given intragastrically, whereas the same effect required 2.04 (1.42) $\mathrm{ml} / \mathrm{kg}$ of intravenous or $10 \mathrm{ml} / \mathrm{kg}$ of intragastric grape juice. White wine (which is extremely poor in tanins) did not have significant results either intravenously $(2.0 \mathrm{ml} / \mathrm{kg})$ or intragastrically $(4.0 \mathrm{ml} / \mathrm{kg})$. With pure ethanol the inhibition of platelet aggregation in vitro, ex vivo, and in vivo usually requires a blood alcohol content of $2 \mathrm{~g} / \mathrm{l}$; the blood alcohol concentration of dogs receiving the red wine saline solution intravenously was $0.28 \mathrm{~g} / \mathrm{l}$.
Why don't we have a pill containing the antioxidant components of red wine which we can add to any kind of beer or spirits? The vasodilating effects of a good red wine are strongly linked to the pleasure of educating the nose and palate, the wine selection, the knowledge of its vineyard, and the degustation in a warm and enjoyable company. Respect for the good and honestly made wines is the best protection against adverse effects of common drinks and spirits: dilated cardiomyopathy, atrial fibrillation, hypertension, liver cirrhosis, traffic accidents, dementia, and polyneuritis are problems of naughty drinkers. The daily consumption of half a bottle of red wine with food does not seem to have any harmful effects other than adding $250 \mathrm{Kcal}$ to your diet!

J-P BROUSTET

Hopital Cardiologique Haut Lévèque,

Pessac, France

1 Keys A. Coronary heart disease in seven countries. Circulation 1970;41(suppl I).

2 Gaziano JM, Buring JE, Breslow JL, et al. Moderate alcohol intake, increased levels of high density lipoproteins, and decreased risks of myocardial infarction. N Engl f Med 1993;329:1829-34.

3 Rimm EB, Klatsky A, Grobbee D, et al. Review of moderate alcohol consumption and reduced risk of coronary heart disease: is the effect due to beer, wine, or spirits? BMF 1996;312:731-6.

4 Friedman GD, Klatsky AL. Is alcohol good for your health? $N$ Engl f Med 1993;329:1882-3.

5 Klatsky AL, Armstrong MA. Friedman GD. Red wine, white wine, liquor, beer, and risk for coronary artery disease hospitalization. Am $\mathcal{F}$ Cardiol 1997;80:416-20.

6 St Léger AS, Cochrane AL, Moore F. Factors associated with cardiomortality in developed countries with particular reference to the consumption of wine. Lancet 1979;i:1017-23.

7 Richard JL. Les facteurs de risque coronarien. Le paradoxe francais. Arch Mal Coeur Vaiss 1987;80(suppl 1):17-21.

8 Renaud S, de Lorgeril M. Wine, alcohol, platelets, and the French paradox for coronary heart disease. Lancet 1992;339:1523-6.

9 Renaud S, de Lorgeril M, Delaye J, et al. Cretan Mediterranean diet for prevention of coronary heart disease. Am f Clin Nutr 1995;61(suppl 6): $1360 \mathrm{~S}-7 \mathrm{~S}$.

10 Orgogozo JM, Dartigues JF, Lafont S, et al. Wine consumption and the elderly: a prospective community study in the Bordeaux area. Rev Neur 1997;153:185-92.

11 Gronbaek M, Deis A, Sorensen TI, et al. Mortality associated with moderate intakes of wine, beer, or spirits. BMF 1995;310:1165-9.

12 Messner T. Petersson B. Alcohol consumption and ischemic heart disease mortality in Sweden. Scand F Soc Med 1996;24:107-13.

13 Jepson RG, Fowkes FG, Donnan PT, et al. Alcohol intake as a risk factor for peripheral arterial disease in the general population in the Edinburgh artery study. Eur 7 Epidemiol 1995;11:9-14.

14 Weisse ME, Eberly B, Person DA. Wine as a digestive aid: comparative antimicrobial effects of bismuth salicylate and red and white wine. BMF 1995; 311:1657-60.

15 Griffith MJ. A new year toast . . . to the cardioprotective effect of alcohol. $\mathrm{Br}$ Heart $\mathcal{F} 1995 ; 73: 8-9$.

16 Frankel EN, Kanner J, German JB, et al. Inhibition of oxidation of human low-density lipoprotein by phenolic substances in red wine. Lancet 1993;341:454-7.

17 Demrow HS, Slane PR, Folts JD. Administration of wine and grape juice inhibits in vivo platelet activity and thrombosis in stenosed canine coronary arteries. Circulation 1995;91:1182-8. 